\title{
On the largest Ichthyosaurus: A new specimen of Ichthyosaurus somersetensis containing an embryo
}

\author{
Dean R. Lomax and Sven Sachs \\ Acta Palaeontologica Polonica 62 (3), 2017: 575-584 doi:https://doi.org/10.4202/app.00376.2017
}

A formerly undescribed Ichthyosaurus specimen from the collection of the Niedersächsisches Landesmuseum (Lower Saxony State Museum) in Hannover, Germany, provides valuable new information. The skeleton was collected from the Lower Jurassic strata (lower Hettangian, Blue Lias Formation) of Doniford Bay, Somerset, UK. However, the specimen is a composite as almost the entire tail has been added and other parts are reconstructed. Regardless of the incomplete preservation, the estimated total length of this individual, based on the skull and precaudal length, is between 300 and $330 \mathrm{~cm}$ and it is thus the largest unequivocal example of the genus Ichthyosaurus. Cranial and postcranial characters, specifically from the maxilla, lacrimal, jugal, the humerus, and the ilium justify a referral to $I$. somersetensis. A fork-like shape of the proximal end of the ilium is unusual and has not been reported for any species of Ichthyosaurus. Likewise the presence of four elements in the third row of the hindfin, indicated by the presence of a bifurcation is novel for the species and has wider implications for the taxonomic utility of hindfins within the genus. The specimen also bears an embryo, which is only the third embryo known for Ichthyosaurus and the first to be positively identified to species level.

Key words: Ichthyosauria, Ichthyosaurus somersetensis, embryo, Jurassic, Hettangian, UK, Somerset.

Dean R. Lomax [dean.lomax@manchester.ac.uk], School of Earth and Environmental Sciences, The University of Manchester, Oxford Road, Manchester, M13 9PL, UK. Sven Sachs [achs.Pal@gmail.com], Naturkundemuseum Bielefeld, Abteilung Geowissenschaften, Adenauerplatz 2, 33602 Bielefeld, Germany; Im Hof 9, 51766 Engelskirchen, Germany.

This is an open-access article distributed under the terms of the Creative Commons Attribution License (for details please see creativecommons.org), which permits unrestricted use, 
distribution, and reproduction in any medium, provided the original author and source are credited.

For Full text $(1,252.9 \mathrm{kB})$ 